\title{
NOTICIAS SOBRE LA DESTRUCCIÓN DEL RETABLO \\ DE TLATELOLCO
}

\author{
JOSÉ' GUADALUPE VICTORIA
}

Al mediar el siglo pasado, México, que apenas treinta años antes había logrado su independencia política de España, vivía un momento muy doloroso: el fin de la guerra fraticida entre conservadores y liberales. Ambos grupos defendían su causa, la que consideraban legítima y más adecuada para la república, en ese entonces, todavía en formación. Sí, hemos de reconocer que las dos facciones presentaron un proyecto - de todo orden- para México, en el que naturalmente contemplaban la cultura. Al respecto, los puntos de vista también diferían diametralmente. Quizá el exceso de entusiasmo por proyectos como el de don Valentín Gómez Farías, referido a la educación, nos ha impedido aquilatar el trabajo de otros hombres, menos explosivos, pero no por eso faltos de imaginación e iniciativa para llevar a la práctica acciones con las que estaban seguros - y el tiempo lo ha confirmado- de ayudar a la formación cultural de la nación.

Todos sabemos quién fue y qué hizo Valentín Gómez Farías, pero con seguridad muchos ignoraban los trabajos y los días de un hombre "bajito", bien parecido, elegantemente vestido y con finos modales. Su nombre era José Bernardo Couto (1803-1862), a quien respetuosamente sus contemporáneos, y aún nosotros, llamaban don Bernardo Couto. ${ }^{1}$

Desempeñó varios cargos públicos y no es dílícil imaginar lo doloroso que le resultó firmar el tratado de paz entre México y los Estados Unidos, en 1848 , por medio del cual - a pesar de lo que se diga oficialmente- el vecino del Norte despojó a México — con el más franco y brutal dolo- de buena parte de su herencia territorial hispánica.

Tal vez esos sinsabores, Couto los mitigó emprendiendo acciones como

${ }^{1}$ José Rojas Garcidueñas, Don José Bernardo Couto, Xalapa, Universidad Veracruzana, 1964, 127 pp. Cuadernos de la Facultad de Filosofía, Letras y Ciencias 24 
la organización de las Galerías de la Academia de San Carlos, para lo cual tocó puertas de iglesias y conventos a fin de que sus guardianes le proporcionaran obras con las cuales formar lo que, en estricto sentido, debe considerarse el primer museo de pintura que tuvo México. ${ }^{2}$

Precisamente una de las puertas que don Bernardo tocó fue la de los padres franciscanos de Santiago Tlatelolco. Solicitó dos cuadros del retablo de la iglesia; aquellos que "representan la Visitación de Santa Isabel y una Aparición del Salvador y Virgen a San Francisco....". ${ }^{3} \mathrm{El}$ retablo, indica el mismo Couto, tenía catorce cuadros, "de los cuales cedieron los padres a la Academia estos dos, que se han reemplazado con copias fieles, colocadas en los sitios mismos que los originales ocupaban". ${ }^{4}$

El tiempo transcurrió, a la llamada Guerra de Tres Años siguió la segunda intervención francesa y el efímero imperio de Maximiliano. Todos saben lo que sucedió en 1867; en el Cerro de las Campanas de Querétaro morían Maximiliano, Miramón y Mejía. Triunfó el liberalismo.

Ahora bien, no todos los conservadores tuvieron un trágico fin. Don Bernardo Couto murió tranquilamente en 1862 en plena invasión francesa. Sin embargo, había conseguido su objetivo: formar las Galerías de Pintura. Es casi seguro que mucho debió dolerle la expedición de las famosísimas Leyes de Reforma, en especial la de la Nacionalización de los Bienes del Clero, en 1859. Esta Ley, aunque resulte difícil aceptarlo, marcó el principio de la destrucción permanente y sistemática del patrimonio artístico de México formado a lo largo de trescientos años, empezando por los edificios. El otrora convento de Santiago Tlatelolco, primero, fue confiscado por el gobierno y destinado a cuartel; la iglesia, más tarde, quedó convertida en bodega de la Aduana, lo cual produjo - era de esperarse- la transformación y degradación paulatina del inmueble. Los cronistas de fines del siglo pasado señalan el aspecto sombrío del edifico y el estado de degradación y abandono en que se encontraba el mobiliario de la iglesia; contándose, entre él, la cátedra donde se suponía que había enseñado fray Bernardino de Sahagún. ${ }^{5}$

García Cubas y Rivera Cambas registran dicho estado de abandono. Citemos el testimonio del primero de estos autores: "triste y de aspecto

\footnotetext{
${ }^{2}$ Abelardo Carrillo y Gariel, Las galerias de pintura de la Academia de San Carlos, México, UNAM, Instituto de Investigaciones Estéticas, $1944,18 \mathrm{pp}$., ils.

3 José Bernardo Couto, Diálogo sobre la historia de la pintura en México, edición preparada por Manuel Toussaint, México, Fondo de Cultura Económica, 1944, pp. 55-56.

${ }_{5}^{4}$ Ibidem.

${ }^{5}$ Manuel Rivera Cambas, México pintoresco, artístico y monumental, México, Ed Valle de México, 1974, t. II, pp. 79-80.
} 
DOI: http://dx.doi.org/10.22201/iie.18703062e.1990.61.1565

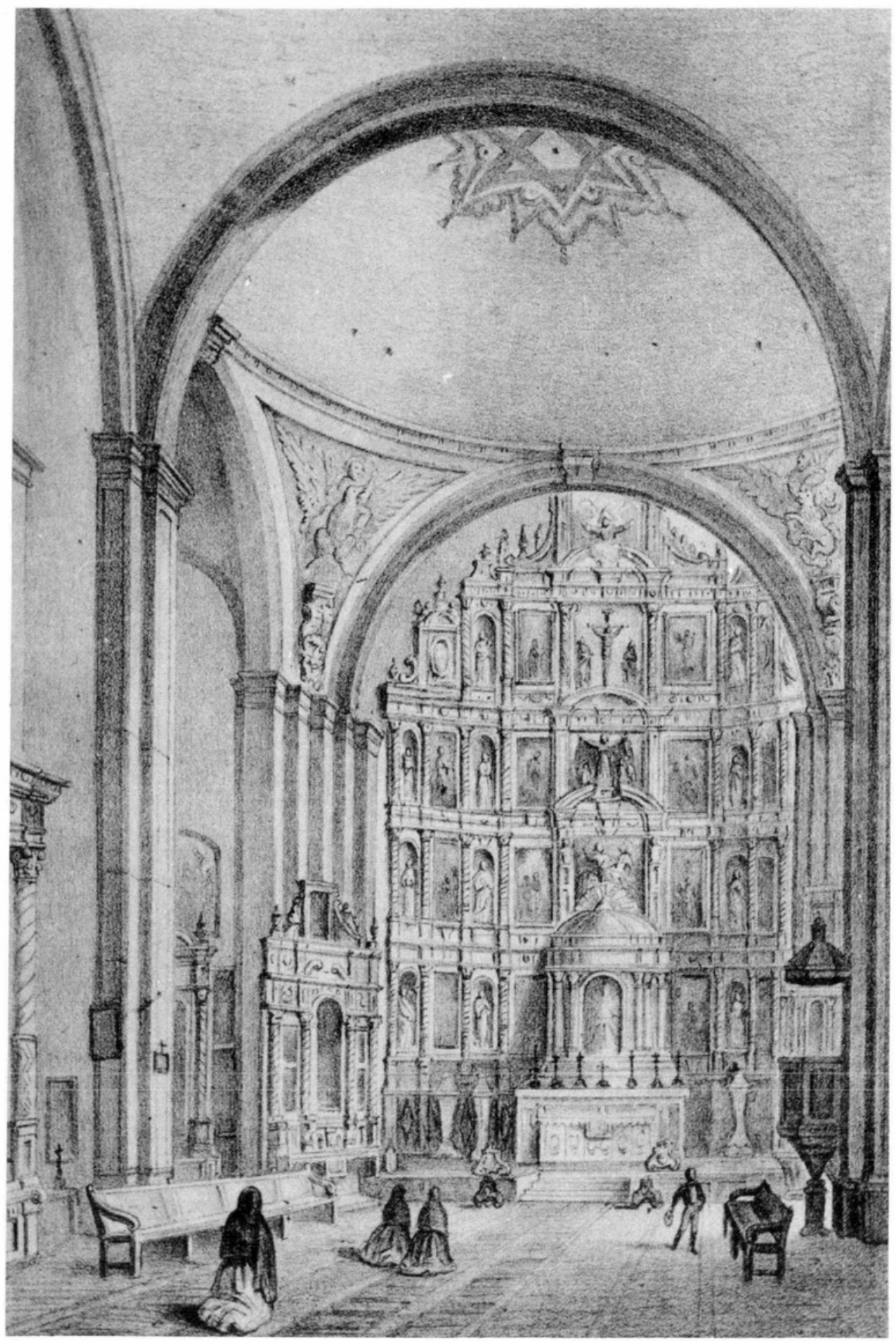

1. Retablo de Santiago Tlatelolco. Litografía publicada en el libro de Ramírez Aparicio Los conventos suprimidos de México. 
DOI: http://dx.doi.org/10.22201/iie.18703062e.1990.61.1565

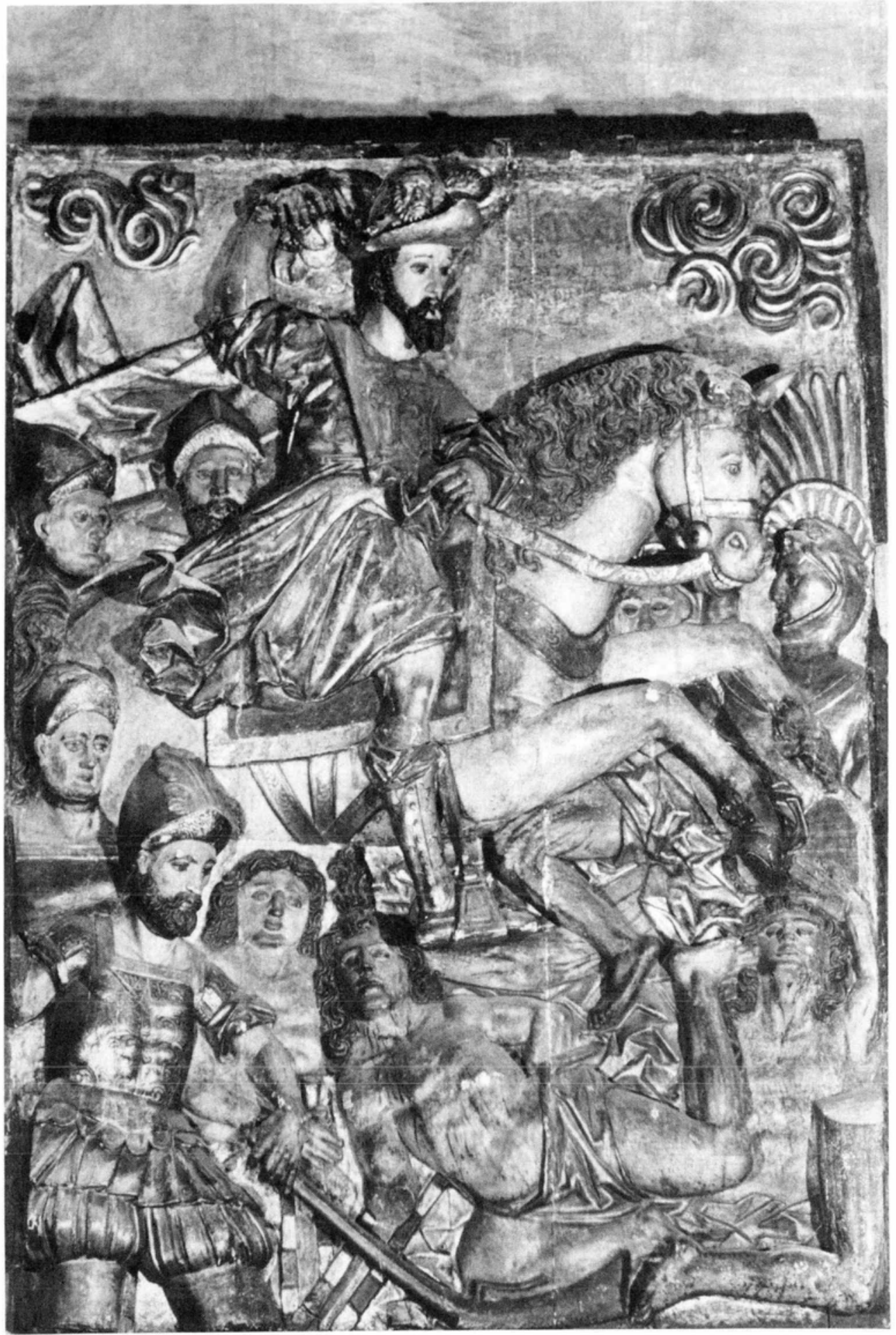

2. Santiago Mataindios. Tabla del desaparecido retablo de Santiago Tlatelolco. Iglesia de Santiago Tlatelolco, D. F. 
sombrío, más sombrío aún que los recuerdos que entraña, se levanta, a lo lejos del centro de la población, la parda mole del ex-templo de Santiago Tlatelolco", 6

Todavía en 1927 la iglesia formaba parte de las oficinas de la Aduana y, gracias a la iniciativa de don Manuel Toussaint -el gran historiador de nuestro arte novohispano-, se logró que el conjunto fuera declarado monumento colonial en $1931 .{ }^{7}$ No obstante, el tiempo pasaba y en 1944 don Rafael García Granados escribía:

La iglesia está situada en el interior de un patio de ferrocarril, convertida en bodega y rodeada de construcciones provisionales que la ocultan y la ensucian material y espiritualmente, sobre el ábside hay una gran caseta de madera cubierta de anuncios llamativos de un refresco. Al norte, una bodega de mampostería cubre por completo el muro. Al frente (el poniente en todos los conventos novohispanos), hay jacales que la cubren parcialmente. En lo que debió ser su atrio y cementerio, barracas construidas con desechos de materiales. Por el sur la iglesia linda con el cuartel El interior del templo que en un tiempo se acondicionó como estufa de desinfección para carros de ferrocarril, es hoy depósito de muebles desechados por inservibles, de las oficinas públicas. Sobre ellos preside un fresco del siglo XVII que representa a San Cristóbal, único resto de la época en que Tlatelolco aún recordaba con veneración haber sido el sitio destinado a impartir la alta cultura a los indios para colocarlos en posición de alternar' en todos los campos con sus conquistadores. ${ }^{8}$

Por fortuna, las voces de los "intelectuales" a veces también cuentan y el Estado se conmueve. A partir de 1944 hubo interés por rescatar el magno edificio tlatelolca empresa que ha conocido varias etapas: la primera de 1944 a 1948 ; la segunda de 1960 a 1964 y la tercera de 1973 a $1975^{\circ}$

La Iglesia fue construida por el célebre fraile franciscano fray Juan de Torquemada. Su construcción duró pocos años -al parecer siete-y en ella colaboraron de manera muy significativa los indigenas tlatelolcas, según el propio testimonio de Torquemada, quien escribió:

No quiero, con palabras encarecidas, ni con mucha multiplicación de ellas, decir lo que estos indios de Tlatelolco han hecho de limosna para la obra de la iglesia de el apóstol Santiago, porque aunque pudiera alargar, la mano, la acorto con solo decir que demás de haber dado graciosamente y sin paga el

${ }_{7}^{6}$ Antonio García Cubas, El libro de mis recuerdos, México, Ed Patria, 1969, 6a ed, p. 126.

${ }^{7}$ Elisa Vargas Lugo, Claustro franciscano de Tlatelolco, México, Secretaría de Relaciones Exteriores, 1975, Colección del Archivo Histórico Diplomático Mexicano, Tercera Epoca, Serie Obras Especiales/3, p 44

${ }^{8}$ Rafael García Granados, citado por Elisa Vargas Lugo, Op cit., p. 44

${ }^{9}$ Ibidem, pp. 43-50. 
trabajo de sus manos, han dado para ayuda a comprar piedra, y cal, para hacerla, más de quince mil pesos que es gran parte de el dinero que en ella y en el retablo he gastado, dando uno ciento, otro doscientos pesos, ya veinte, treinta, cuatro y diez, conforme el caudal [que] cada uno ha tenido ... De manera que no se tiene por hijo leal de el apóstol el que no contribuye y le da algo.... 10

La iglesia y el retablo se dedicaron en 1610 , tal como indica el historiador mestizo Domingo de San Antón Muñon Chimalpain Cuauhtlehuanitzin en su Diario.

Hoy sábado, al toque de campanas, por la tarde, 14 de julio de mil seiscientos diez años, siendo las vísperas de Sántiago apóstol, se consagró el templo, cuando ya se acabó de edificar la iglesia de Tlatelolco... Y también entonces quedó colocado el nuevo retablo, al día siguiente, domingo, cuando fue la fiesta de Santiago, el 15 de julio. Entonces hubo alegría, se hizo fiesta en Tlatelolco. Así se inauguró la iglesia, la que terminó, vino a concluir con sus manos el padre Juan de Torquemada .... 11

Los Anales de Tlatelolco, siempre más escuetos, indican: "Este templo lo acabó el muy reverendo padre fray Juan de Torquemada, guardián..... En verdad en siete años se acabó, vino a terminarse en $1610_{\text {..." }}{ }^{12}$

Fray Juan no indica quién diseñó el retablo; en cambio da cuenta de los artistas que lo realizaron. Contó con un equipo de artesanos muy capaces, a quienes tributa un sentido elogio, pues dice:

Hay entalladores (y los había en su infidelidad) muy primos, en especial en esta ciudad de México, donde, con la comunicación de los españoles, se han perfeccionado y pulido muchos, de los cuales conozco muchos que hacen la madera de lo que se obligan los pintores españoles; y hay en esta parcialidad de Santiago (entre otros) uno, que ninguno de los nuestros le hace ventaja; y él excede a muchos Llámase Miguel Mauricio, de mucho y delicado ingenio, con el cual, y con los otros digo haber en esta parte de ciudad, hice el retablo de este santo templo, que edifiqué en ésta, que es una de las mejores cosas del reino. Labran talla y escultura, así grande como chica, y hacen imágenes y santos de hueso, de mucha curiosidad y por serlo tanto los llevan a España, como llevan también los crucifijos huccos de caña, que siendo de la corpulencia de un hombre y mayor, pesan tan poco que puede llevarlos un niño de pocas fuerzas, tan perfectos, tan proporcionados y devotos, que no pueden ser mejores ${ }^{13}$

\footnotetext{
${ }^{10}$ Fray Juan de Torquemada, Monarquía Indiana, México, UNAM, Instituto de Investigaciones Históricas, 1975-1983, 3a ed., vol. V, pp 324-325

${ }^{11}$ Domingo Francisco de San Antón Muñon Cuauhtlehuanitzin, Diario, citado en Anales de Tlatelolco, p 179

${ }_{12}$ Anales de Tlatelolco, p. 179

${ }^{13}$ Fray Juan Torquemada, $O p$. cit, v IV, p 255
} 
Además de los artistas indígenas que elaboraron el retablo de Tlatelolco, participó el célebre pintor Baltasar de Echave Orio, cuya maestría deslumbró al padre Torquemada, quien no dudó en calificarlo de "único en su arte". Este artista, seguramente, fue el autor del diseño del retablo; aunque siguiendo, tal vez, las indicaciones del padre Torquemada en cuanto al programa iconográfico de la obra. El retablo indica el mismo fraile fue obra costosa "está apreciado en veinte y un mil pesos. Y este han labrado los oficiales de valde, poniendo sus manos y trabajo graciosamente, llegando a muchos ducados lo que se ha gastado en materiales y pincel..."

El retablo dejó satisfecho al fraile y a los fieles. Vetancour, que conoció la obra a fines del siglo XVII (1697), aunque modificada, dice "el retablo es de todo costo y primor, cuyas imágenes de talla admiran a los maestros". ${ }^{15} \mathrm{Y}$ añade que la iglesia "tiene muchos altares y retablos muy costosos, y curiosamente fabricados. Entre ellos uno de N. Señora de Guadalupe Mexicana, que es de los cantores, que al paso que son de los más diestros en la música, pues de muchos de ellos se ha valido la catedral para su capilla, son en celebrar la imagen muy devotos." ${ }^{16}$

Ahora bien, es un poco extraño que Vetancour, al hablar de la iglesia, sólo diga: "es de bóvedas hornacinas con su crucero, muy hermosa y de las mejores del reino", sin indicar cuál era el estado material que guardaba; mismo que debió ser un tanto deplorable pues en 1700 el inmueble fue objeto de grandes obras de consolidación, según se informa en un Sermón que predicó fray Juan de Torres. ${ }^{17}$ Desafortunadamente este fraile, en su empeño de exaltar la personalidad de fray Bartolomé Giner y el papel que desempeñó en la obra, no especifica en qué consistieron dichos trabajos de renovación.

Cabe pensar que para ese entonces el retablo ya había sido objeto de una "remodelación" o "renovación" porque, según se observa en la litografía publicada por Ramírez Aparicio, las columnas son salomónicas; e igual

\footnotetext{
${ }^{14}$ Ibidem

${ }^{15}$ Fray Agustín de Vetancour, Chronica de la provincia del Santo Evangelio de México, México. Imprenta de Doña María de Benavides Viuda de Ribera, 1697, p. 67

${ }^{16} \mathrm{Ibidem}$

${ }^{17}$ Fray Juan de Torres, Sermón gue en la renovación del lemplo de Santiago de esta ciudad de México, dedicado el día 16 de enero de 1701, discurrío y dijo el Padre, hijo de la Santa Provincia del Santo Evangelio y Lector de Teologia en el Colegio de San Buenaventura de México; presente la santa, docta y venerable Provincia del Santo Eviangelio con su ejemplar superior prelado N. Rmo. $P$ $F r$ Bartholomé Giner, lector jubilado, padre de la Santa Provincia de Valencia, Comisario General de todos los de esta Nueva España, a quien se dedica y consagra, dáse a la estampa a devación y expensas del señor licenciado D. Luis Sandoval y Zapata, cura dignisimo que ha sido de la parroquia de Santa Catharina Martir de esta Corte, México, Juan Joseph Guillena Carrascoso, 1701.
} 
tipo de apoyo se observa en los retablos esquineros - dispuestos a manera de chaflán-de la capilla mayor.

No es posible, por ahora, precisar el momento en que se llevó a cabo ese cambio. Suponemos que tuvo lugar durante el último tercio del siglo XVII cuando la columna salomónica era el apoyo preferido por los maestros retablistas. Los frailes de Tlatelolco - como ocurrió en tantos otros casos-debieron aspirar a contar, en su iglesia, con retablos fabricados bajo los lineamientos de la nueva moda; al tiempo que decidirían renovar el retablo mayor conservando las antiguas pinturas y los relieves.

El retablo, tal como se observa en la litografia, constaba de cuatro cuerpos y un remate. En sentido vertical se distinguen ocho calles siendo más ancha la del centro, flanqueada por dos en las que están distribuidas ocho pinturas. En las dos calles siguientes hay esculturas y, al lado de éstas, se distinguen seis lienzos. En las calles de los extremos también hay esculturas.

Llama la atención -en opinión de Jorge Alberto Manrique - que en los extremos del último cuerpo y el remate se hayan conservado elementos de filiación manierista como tarjas y remates piramidales; los cuales tienen relación con los del retablo de Xochimilco Obra esta última atribuida a Baltasar de Echave Orio.

Desafortunadamente la litografía no permite precisar la distribución de los temas de las pinturas en el retablo; en cambio es muy precisa la iconografía de los relieves en la calle central. De abajo hacia arriba, en el segundo registro, se ve el magnífico relieve de Santiago mata indios, según lo denominó Francisco de la Maza. ${ }^{18}$ Arriba, en el tercer registro, se aprecia lo que, suponemos, es un Patrocinio de San Francisco con donantes; representación que mantiene similitud con el relieve de San Bernardino con caciques indígenas, del retablo de Xochimilco ${ }^{19}$ En el cuarto registro se ve un Calvario y, por último, en el remate está la figura del Padre Eterno; tal como se observa en otros retablos de la época.

Al parecer, durante gran parte del siglo XVIII, la iglesia no sufrió mayores alteraciones. Pero en 1763 fray Manuel de Nájera, comisario general de la Nueva España, según está indicado en una cartela del fresco que representa a San Cristóbal -sobre la entrada lateral de la iglesiaordenó realizar algunos trabajos; entre otros "se retocó esta imagen; se

\footnotetext{
${ }^{18}$ Francisco de la Maza, "iSantiago y a ellos!", Páginas de Arte y de Historia, México, INAH, 1971, pp. 177-222

${ }^{19}$ Francisco de la Maza, "El 'San Bernardino de Xochimilco' y sus caciques domésticos", México en la Cultura, Suplemento cultural de Novedades, 28 de mayo de 1950
} 
Raf (?) y blanqueó toda esta iglesia por dentro y fuera y se doraron de nuevo el retablo mayor y los dos laterales de sus pilastras".

No es posible saber, por ahora, si el retablo fue objeto de modificaciones posteriores, especialmente durante el periodo neoclásico. En la litografia se aprecia una especie de baldaquino cuyas columnas clásicas permitirían suponer un arreglo de principios del siglo XIX.

Como quiera que sea, puede afirmarse, en términos generales que desde los tiempos del padre Nájera hasta la Exclaustración, el retablo permaneció incólume. Don José Bernardo Couto, indicamos en otro lugar, solicitó dos cuadros que sustituyó con copias. Y con las palabras de don Manuel Toussaint hemos de repetir: "iInsigne y honrado varón! iCómo había de pensar que de esos catorce cuadros del retablo de Tlatelolco sólo se salvarían para la posteridad los dos que él retiró con el beneplácito de los frailes franciscanos y llevando su escrúpulo hasta sustituirlos con fieles copias que también desaparecieron! ${ }^{\text {20 }}$

Esos dos cuadros, la Visitación y la Porciúncula, estuvieron primero en las Galerías de Pintura y, en 1964, al inaugurarse la Pinacoteca Virreinal de San Diego, pasaron a formar parte de sus fondos. ${ }^{21} \mathrm{El} \mathrm{mismo} \mathrm{Toussaint}$ piensa que otros cuadros de Echave Orio, conservados en el mismo museo, tal vez provienen del retablo de Tlatelolco.

Vale la pena mencionar algunos datos sobre Echave Orio: era de origen vasco; tal vez nació en 1548 y vino a México alrededor de 1575. Acá aprendió el oficio de pintor con su suegro Francisco de Zumaya. Además del retablo de Tlatelolco, hizo el de los jesuitas de México y quizá también el de Xochimilco. Muchos fueron los días que, con seguridad, pasó en Tlatelolco, al lado de fray Juan de Torquemada, quien pese a su mal carácter supo apreciar el trabajo de Echave y el de los escultores indígenas como Miguel Mauricio, quien bien pudo haber tallado el relieve de Santiago

Si así fuera, el escultor indígena debe ser considerado como uno de los más importantes de ese tiempo, en el ámbito novohispano. El relieve de Santiago, escribe Francisco de la Maza, "no sabemos cómo se salvó de los iconoclastas del siglo XIX, pero manos piadosas lo han devuelto al templo

20 José Bernardo Couto, Op. cit., p. 56. Elisa Vargas Lugo y quien esto escribe, en 1985 , localizaron en una colección particular de la Ciudad de México, un cuadro exactamente igual al de Echave Orio que representa La Porciúncula. Suponemos que se trata de la copia mandada hacer por Couto y desaparecida con los otros lienzos

${ }^{21}$ Vid, Abelardo Carrillo y Gabriel, Op. cit, y Carmen Andrade, La pinacoteca virreinal, México, SEP, 1974, Sepsetentas 170. 
de San Francisco [de México] de donde creo deberá volver al de Santiago Tlatelolco". ${ }^{22}$

Por fortuna, en años recientes, al ser entregada nuevamente la iglesia a los franciscanos, el relieve fue trasladado a su lugar de origen. Ahí está ahora, aunque es difícil de admirar dada la pésima iluminación que dieron a la iglesia los restauradores.

No obstante, junto con los cuadros de Echave Orio, es una ínfima parte de la memoria de la sociedad tlatelolca y mudo testigo de los efectos que -indirectamente, si se quiere-produjo la reforma liberal decimonónica. iSantiago y a ellos!, grito de guerra de los conquistadores, trasuntado en el relieve, parece haber sido parafraseado por los reformistas mexicanos. Sí, quizá no faltó entre ellos quien exclamara: Viva el liberalismo y a ellos! Los monumentos...

${ }^{22}$ Francisco de la Maza, "iSantiago y a ellos!". 